\title{
Global seismic data reveal little water in the mantle transition zone
}

\author{
C. Houser ${ }^{\mathrm{a}, *}$ \\ ${ }^{a}$ Earth-Life Science Institute, Tokyo Institute of Technology, 2-12-1-IE-1 Ookayama, Meguro-ku, Tokyo, \\ 152-8550, Japan.
}

\begin{abstract}
Knowledge of the Earth's present water content is necessary to constrain the amount of water and other volatiles the Earth acquired during its formation and the amount that is cycled back into the interior from the surface. This study compares 410 and $660 \mathrm{~km}$ discontinuity depth with shear wave tomography within the mantle transition zone to identify regions with seismic signals consistent with water. The depth of the 410 and $660 \mathrm{~km}$ discontinuities is determined from a large updated dataset of SS-S410S and SS-S660S differential travel times, known as SS precursors. The discontinuity depths measured from binning and stacking the SS precursor data are then compared to the shear velocity model HMSL-S06 in the transition zone. Mapping all the possible combinations, very few locations match the predictions from mineral physics for the effects of water on discontinuity depth and shear velocity. The predictions, although not yet measured at actual transition zone temperatures and pressures, are a shallow $410 \mathrm{~km}$ discontinuity, a deep $660 \mathrm{~km}$ discontinuity, and a slow shear velocity. Only $8 \%$ of the bins with high-quality data are consistent with these predictions, and the calculated average water content within these bins is around $0.6 \mathrm{wt} \%$. A few isolated locations have patterns of velocity/topography that are consistent with water, while there are large regional-scale patterns consistent with cold/hot temperature anomalies. Combining this global analysis of long period seismic data and the current mineral physics predictions for water in transition zone minerals, I find that the mantle transition zone is generally dry, containing less than one Earth ocean of water. Although subduction zones could be locally hydrated, the combined discontinuity and velocity data show no evidence that wadsleyite or ringwoodite have been globally hydrated by subduction or initial Earth conditions.
\end{abstract}

Keywords: mantle transition zone, mantle discontinuities, mantle shear velocity, SS precursors,

\footnotetext{
${ }^{*}$ Corresponding author

Email address: chouser@elsi.jp (C. Houser)
}

Preprint submitted to Elsevier

March 15, 2016

(C) 2016. This manuscript version is made available under the Elsevier user license http://www.elsevier.com/open-access/userlicense/1.0/ 
mantle phase transitions

\section{Introduction}

Understanding the Earth's water budget through time requires constraining the amount of water that is currently present in the Earth's interior. The amount of water in the interior could be decreasing over time by degassing at divergent plate boundaries, increasing by transport within subducting oceanic plates, or in balance between these processes. Water may be able to reach the mantle transition zone within metastable mineral phases in cold subducting oceanic lithosphere (i.e. slabs) (Angel et al., 2001). Mineral physics studies have shown that nominally anhydrous wadsleyite and ringwoodite could contain close to 3\% water (Inoue et al., 1995; Kohlstedt et al., 1996), which is a storage capacity of up to 10 oceans of water. Since planetary formation models are sensitive to the Earth's initial water content, it is necessary to put bounds on the amount of water in this potential reservoir. The mantle transition zone is here defined by global seismic reflectors consistent with phase transitions in the olivine component of the mantle at approximately $410 \mathrm{~km}$ (olivine to wadsleyite) and $660 \mathrm{~km}$ depth (ringwoodite to bridgmanite and ferropericlase).

Several studies have measured the effects of water on the properties of transition zone minerals and will be summarized briefly here. While wadsleyite and ringwoodite can hold up $3 \mathrm{wt} . \%$ water at ambient conditions (Smyth et al., 2004; Ohtani et al., 2000), the capacity for water storage decreases with increasing temperature such that 1-2 wt.\% is often predicted at transition zone temperatures and pressures (Bolfan-Casanova et al., 2006; Mao et al., 2008), but could be as low as 0.2 wt.\% (Dixon et al., 2002; Huang et al., 2005; Hirschmann, 2006; Inoue et al., 2010; Mao et al., 2012). Inoue et al. (2004) found that the seismologically observed bulk sound speed contrast across $410 \mathrm{~km}$ discontinuity is consistent with a bulk composition that is $60 \%$ olivine and $1.5 \mathrm{wt} . \%$ water. They also measured a lower density and bulk sound velocity for hydrous compared to anhydrous wadsleyite. $\mathrm{Ab}$ initio calculations indicate that both shear and compressional velocity will decrease by $1.5 \%$ for each 1.0 wt.\% water added to hydrous wadsleyite (up to the maximum of $3.3 \mathrm{wt} . \%$ )(Tsuchiya and Tsuchiya, 2009) . Smyth and Frost (2002) observed that water will stabilize wadsleyite relative to olivine, and therefore decrease the depth of the transition such that the $410 \mathrm{~km}$ discontinuity would be shallower (lower pressure) in the presence of water. By the same reasoning, since water is more compatible in ringwoodite than bridgmanite and ferropericlase, the $660 \mathrm{~km}$ discontinuity is deeper (higher pressure) for a hydrous peridotite composition (Litasov et al., 2005). In addition to these 
experimental results, Pearson et al. (2014) measured 1.4 wt.\% water in a ringwoodite inclusion in a natural diamond.

Thio et al. (2016) point out that there have been no experiments that measure properties of transition zone materials at both the high temperatures and pressures for water-bearing phases. From a thermodynamic point of view, since water is more easily incorporated into wadsleyite than olivine at the top of the transition zone and ringwoodite than bridgmanite and ferropericlase at the base of the transition zone, water will expand the stability fields of wadsleyite and ringwoodite and increase the thickness of the transition zone. This scenario could change if other minerals that can incorporate water become stable at the high temperatures and pressures of the transition zone. However, the consensus from mineral physics (Jacobsen and Smyth, 2006; Bolfan-Casanova et al., 2006 ) is that the seismic signature of 1-2 wt.\% water present in the mantle transition zone is slow shear velocity, shallow $410 \mathrm{~km}$ discontinuity, and deep $660 \mathrm{~km}$ discontinuity, Figure 1.

Mineral physics predictions can be tested by comparing global maps of shear wave velocity and discontinuity depth (Helffrich, 2002). Despite the fact that global tomographic models have decreased resolution in the mantle transition zone, most tomographic models are in generally good agreement about the large scale features such as the emergence of subducted slabs (Ritsema et al., 2004). Global maps of discontinuity topography are constructed by measuring the time difference between the surface-reflected SS phase and the S410S and S660S reflections (see Figure 2 and further discussion in the methods section). Although they use different methods, there are several reliable global discontinuity studies from SS precursors which are also in relatively good agreement about the large scale features (Deuss, 2009). Thus, general conclusions can be made by combining any tomography and discontinuity model to examine which regions may be compatible with the presence of water. Here I compare an updated map of discontinuity topography to the shear velocity model HMSL-S06 (Houser et al., 2008b).

\section{Method}

I use the same data and methodology as (Houser et al., 2008a) to obtain the SS-S410S and SS-S66SS differential times from 2006 to 2010. Since the S410S and S660S arrivals are too faint to be seen above the noise on most individual seismograms, I stack seismograms with high quality SS signals whose bounce points lie within $5^{\circ}$ radius bins (Figure 2). The traces are first deconvolved by the main SS pulse and then aligned and stacked according to their arrival times measured using 
cluster analysis (Houser et al., 2008b). The SS-S410S and SS-S660S differential times are converted to depth using 20 second PREM (Dziewonski and Anderson, 1981). For a full description of the stacking procedure, see Houser et al. (2008a).

Table 1: SS Precursor Arrival Time Measurements

\begin{tabular}{|c|c|c|c|}
\hline Author & Start & End & Number of Data \\
\hline Flanagan and Shearer 1998 & 1976 & 1995 & 13,467 \\
\hline Houser et al. 2008a & 1995 & 2005 & 26,348 \\
\hline Update & 2006 & 2010 & 31,577 \\
\hline Total for this study & 1976 & 2010 & 71,392 \\
\hline
\end{tabular}

This update increases the amount of measured SS arrival times by over $40 \%$ (Table 1) and improves the SS precursor stack quality in the northern Pacific, southern Pacific, eastern Asia, Indian ocean, northern South America, and north Atlantic. Figure 3 shows the increase in the number of traces per stack in each bin and representative stacks from the many different regions before and after the update. While the improvement in coverage is dominant in the Pacific and eastern Asia, there is improvement in a variety of tectonic settings. The resulting maps of topography on the 410 and $660 \mathrm{~km}$ discontinuity and transition zone thickness are shown in Figure 4 . I used the total combined dataset from Flanagan and Shearer (1998), Houser et al. (2008a), and the updated dataset of 2006-2010 for the SS precursor stacking. While the update improves coverage in several regions, there are still many areas in the southern hemisphere that have too few data to obtain a quality stack. In Figures 4, 6 and 7, I do not plot areas where the depth error exceeds $20 \mathrm{~km}$.

I compare the updated discontinuity topography to a shear velocity model with the same inversion method as HMSL-S06 but parameterized with $6^{\circ}$ equal-area blocks (Figure 5). I use the $530-660 \mathrm{~km}$ depth layer within the transition zone parameterized at $6^{\circ}$ (not $4^{\circ}$ as in the original HMSL-S06 (Houser et al., 2008b)) to be consistent with the broader sensitivity of the SS precursors. The upper mantle is constrained by surface wave phase velocity maps of Love Bassin et al. (2000) and Rayleigh (Laske 2004, personal communication) waves at frequencies of 4-15 $\mathrm{mHz}$, where the lowest frequencies are sensitive to transition zone structure. Although HMSL-S06 does not use body waves that turn within the transition zone because the arrival times are complicated by the triplications from the 410 and $660 \mathrm{~km}$ discontinuities, the body waves turning in the uppermost 
lower mantle are partially sensitive to transition zone structure. I do not include the compressional wave model HMSL-P06 in this analysis since the upper mantle of that model is simply a scaled version of the shear wave model and thus does not add any additional constraint.

To compare the discontinuity topography and shear velocity, I use the analysis first described in Houser and Williams (2010). The combination of 410 and $660 \mathrm{~km}$ discontinuity depth and fast/slow seismic velocity anomaly results in 8 possible cases relating these three observations. The left side of Figure 6 shows the western (top) and eastern (bottom) hemispheres, where each circle is the bin location for the highest quality stacked precursor data. For instance, a stacked trace that has a shallower-than-average $410 \mathrm{~km}$ discontinuity and a deeper-than-average $660 \mathrm{~km}$ discontinuity will plot as dark blue if the seismic velocity is fast, or purple if the seismic velocity is slow. In general, cool colors are used for fast seismic velocities and warm colors are used for slow seismic velocities. The seismic velocity used is the $600 \mathrm{~km}$ depth slice of the $6^{\circ}$ shear velocity model HMSL-S06 shown in Figure 5. The right side of Figure 6 highlights the 105 of 1301 bin locations (8\%) that are consistent with water (slow shear velocity, shallow $410 \mathrm{~km}$ discontinuity, deep $660 \mathrm{~km}$ discontinuity).

In order to examine any regional velocity-topography relationships, I test the observed patterns against random arrays of points on a globe. For instance, there are a few locations in the right panel of Figure 6 where bins consistent with water appear to cluster, but it is not possible to say a region is consistent with water unless the clustering exceeds the clustering that could occur by random chance. I assign each of the bin locations a random value between 1-8 for the 8 possible relations of velocity and topography shown in Figure 6, then count how many bins with the same value were found within a radius of $20^{\circ}$. This process is performed 1000 times to compute the mean and standard deviation for the number of bins with the same value that would be expected if the values were random. For most locations, the mean value is 4-7 and $\sigma$ is around 1.5. The maps in Figure 7 show the bin locations for each of the 8 cases separately where $+\mathrm{Vs}=$ fast, $-\mathrm{Vs}$ $=$ slow,$-410 / 660=$ shallow,$+410 / 660=$ deep. The locations for which there are more nearby bins $($ mean $+2 \sigma)$ with the same value compared to random are colored according to the scheme in Figure 6 . The bins that are within $2 \sigma$ are plotted as empty circles. A distance of $20^{\circ}$ was chosen since it is small enough to represent regional patterns, but large enough to get good statistics in the poorly sampled regions.

The signals in seismic data are dominated by the effects of temperature in many regions, but there are very few regions hydrated enough to produce a dominant seismic signal. Cases 1-6 show 
that the velocity-topography relationship can be statistically significant across large regions of the globe. Case 1 (fast shear velocity, shallow $410 \mathrm{~km}$ discontinuity, deep $660 \mathrm{~km}$ discontinuity) is found in subduction areas and is consistent with the expected signals from a cold thermal anomaly. Likewise, Case 6 with a low shear velocity, deep $410 \mathrm{~km}$ discontinuity, and shallow $660 \mathrm{~km}$ discontinuity (the signals expected for a vertically continuous warm thermal anomaly (Deuss et al., 2013)) is statistically significant across the mid Pacific. Since the $660 \mathrm{~km}$ discontinuity might actually be depressed in hot regions due to the majorite phase transition (Hirose, 2002; Houser and Williams, 2010), Case 4 with low shear velocity, deep $410 \mathrm{~km}$ discontinuity, and deep $660 \mathrm{~km}$ discontinuity may also indicate a temperature anomaly. Indeed, this pattern is observed to be statistically significant across the mid Pacific. Case 8 of Figure 7 shows that only a few spots around Antarctica and under Brazil have a signal for water that is greater than random. Although the eye detects a possible clustering in the Indian Ocean and New Guinea, this clustering does not appear to be statistically significant.

To calculate the upper-limit of water concentration in the bins with the water signal, I apply Equation 1 from Suetsugu et al. (2006), without the temperature dependent terms, to the seismic observations of transition zone topography and velocity.

$$
\begin{array}{r}
\delta d=\frac{\partial d}{\partial W} \delta W \\
\delta V s=\frac{\partial(\delta V s)}{\partial W} \delta W
\end{array}
$$

where $\delta d$ is the departure from the average depth $(\mathrm{km})$ of the 410 or $660 \mathrm{~km}$ discontinuities shown in Figure 4, $\delta V s \%$ is the observed shear velocity anomaly shown in Figure 5 , and $W$ is the water content (wt.\%). For comparison with other studies, I choose the same values as Mao et al. (2012):

$\frac{\partial(\delta V / V)}{\partial W}=-4.5$ vel\%/wt.\% (Mao et al., 2012)

$\frac{\partial d_{410}}{\partial W}=-15 \mathrm{~km} / \mathrm{wt} . \%$ (Smyth and Frost, 2002)

$\frac{\partial d_{660}}{\partial W}=6 \mathrm{~km} / \mathrm{wt} . \%$ (Higo et al., 2001)

Using these values and the measured $410 \mathrm{~km}$ and $660 \mathrm{~km}$ discontinuity topography and shear velocity, I calculate the upper limit on the water content since I ignore the temperature-dependent terms. The distribution of the average water content measured in each of the 105 bins consistent with water is shown in the left side of Figure 8 . The overall average value is 0.6 wt\% water in 
these portions of the mantle transition zone. This is slightly larger than the $0.1 \%$ reported by Mao et al. (2012), but expected since I do not factor in the effects of temperature. Suetsugu et al. (2006) obtain larger values for water content in subduction zones because they use a smaller value of $\frac{\partial d}{\partial W}(2.7 \mathrm{~km} / \mathrm{wt} . \%)$ and do not use the $410 \mathrm{~km}$ discontinuity topography in their calculations. The right hand side of Figure 8 overlays the water content values separately for each type of data; $410 \mathrm{~km}$ discontinuity topography, $660 \mathrm{~km}$ discontinuity topography, and shear velocity anomaly. The very low (0-0.2 wt.\%) values predominantly come from the velocity measurements, while the very high values (1.5-3.0 wt.\%) come from the $660 \mathrm{~km}$ discontinuity topography measurements. Mao et al. (2012) report that the sensitivity of shear velocity to temperature increases at transition zone temperatures compared to room temperature. Since the shear velocity variations are about $0.5 \%$ on average, the magnitude of the water anomaly is around $0.1 \mathrm{wt} . \%$. Likewise, although the 410 and $660 \mathrm{~km}$ discontinuities have about the same topography range, the $660 \mathrm{~km}$ discontinuity measurements lead to higher estimates of water content since the sensitivity is reported to be half that of the $410 \mathrm{~km}$ discontinuity.

\section{Discussion}

The global long period seismic data observations reported here are not compatible with the mineral physics predictions regarding the effects of water on transition zone minerals . Since most mantle shear velocity models are in general agreement, and most maps of discontinuity topography are in general agreement, the results shown here are not strongly dependent on the models. The seismic data presented here are sensitive to lateral variations in rock properties and do not directly measure the background level of hydration. If the transition zone is completely saturated or completely devoid of water, then there would be no seismic signals from lateral changes in water content. Interpreting the seismic signals in terms of changes in water content applies in the intermediate case where there is some amount of water in the transition zone even if the background level is not known.

The sharpness of the $410 \mathrm{~km}$ discontinuity has been considered an indicator of water content since the phase transition interval will extend from $4 \mathrm{~km}$ in the dry case to up to $40 \mathrm{~km}$ with complete saturation (Wood, 1995; Helffrich and Wood, 1996; Smyth and Frost, 2002). Most short period studies find the $410 \mathrm{~km}$ discontinuity has a sharpness less than $10 \mathrm{~km}$ (Benz and Vidale, 1993; Neele, 1996; Xu et al., 2003) which can be interpreted as evidence against hydrous wadsleyite. 
However, the relative proportions of the initial and final phases within the phase loop is often not linear, so a sharp seismic discontinuity can arise even from a broad phase transition (Stixrude, 1997). Hydrogen also diffuses quickly which can sharpen the boundary in areas where vertical flow is slower than the diffusion rate (Smyth and Frost, 2002).

Recent seismic studies have had mixed results identifying water in the transition zone. Cammarano and Romanowicz (2007) find that their seismic observations are best explained by an upper mantle that is faster and a transition zone that is slower than predicted for pyrolite. While the reduced seismic velocities within the transition zone could be due to water, water does not explain their upper mantle measurements, and they favor a gradual increase in the proportion of garnet with depth. Meier et al. (2009) jointly invert for surface wave velocity and topography and see different structure in the $410 \mathrm{~km}$ discontinuity topography than reported here. Since their 410 $\mathrm{km}$ discontinuity is elevated under the Pacific, they propose that the uplift and the slow velocity there could be due to water. Their $410 \mathrm{~km}$ discontinuity topography is highly correlated with the $660 \mathrm{~km}$ discontinuity topography and an ocean-continent function, indicating that their data may have difficulty resolving structure of the discontinuities. Their results do not seem compatible with precursor data since the highest quality SS precursors are under the Pacific, with over 1000 traces contributing to the stacks in this region, and a depressed $410 \mathrm{~km}$ discontinuity under the Pacific is also observed in other precursor studies (Gu et al., 2003; Lawrence and Shearer, 2008; Deuss, 2009). For an overview of earlier seismic studies regarding water in the transition zone, see (Deuss et al., 2013).

Globally, the 410 and $660 \mathrm{~km}$ discontinuities are not correlated with each other, rather than anti-correlated as expected for both temperature or water (Houser et al., 2008a). If water is not distributed evenly with depth in the transition zone, then perhaps it is collecting either in the ringwoodite or the wadsleyite due to material flowing across the transition zone. In which case, the $410 \mathrm{~km}$ discontinuity and the shear velocity should be consistent with water in upwelling regions and likewise for the $660 \mathrm{~km}$ discontinuity and shear velocity in downwelling regions. The strongest signals in the transition zone topography and velocities are a thick transition zone and fast velocities in the circum-Pacific and a thin transition zone and slow velocities under the Pacific. The correlation of the $410 \mathrm{~km}$ discontinuity topography and shear velocity should be stronger than the $660 \mathrm{~km}$ discontinuity and shear velocity since water is more compatible in wadsleyite than ringwoodite. However, the depressed $410 \mathrm{~km}$ discontinuity and slow shear velocity where the mantle 
is flowing upwards under the Pacific plate is not consistent with water, but with temperature. The corresponding argument that the $660 \mathrm{~km}$ discontinuity and shear velocity should be correlated in downwellings is difficult to assess because of the strong temperature signal in a down going slab. While studies such as Litasov et al. (2005) say that 660 depth is more sensitive to water than temperature, such that a thick transition zone is wet, the fast velocities of the slab due to the cold temperatures could hide the signal from water. Thus, more regional studies are necessary to evaluate distribution and concentration of water in areas of active subduction (Suetsugu et al., 2006; Zheng et al., 2007).

While the global seismic observations presented here find that the mantle transition zone is generally dry, the recent observation of hydrous ringwoodite in diamonds from a kimberlite pipe in Brazil (Pearson et al., 2014) has been interpreted as evidence for close to 1 wt.\% water in ringwoodite. Another interpretation is that water is not compatible at transition zone temperatures and pressures for long time scales and will result in melting instabilities that lead to the formation of such kimberlite pipes. Schmerr and Garnero (2007) provide a detailed examination of the transition zone beneath South America using SS precursors, but do not observe the same topography pattern under Brazil reported here. They find a slightly depressed $410 \mathrm{~km}$ discontinuity and a slightly elevated $660 \mathrm{~km}$ discontinuity. Their observations in the region of the slab suggest local dehydration of the slab and storage of water 10s of kilometers below the uplifted $410 \mathrm{~km}$ discontinuity, but no regional hydration of the entire transition zone. In addition, Lessing et al. (2014)'s observations of PP and SS precursors beneath India and western China, an area with 100s of millions of years of subduction of the oceanic Tethys and Indian plates (Stamplli and Borel, 2002), show no signal consistent with hydration of the transition zone.

The assertion here that the mantle transition zone is generally dry is compatible with recent results that water could be stable in some mineral structures allowing water to pass into the lower mantle. Although the hydrous phase $\mathrm{H}$ could be stable in the lower mantle at low temperatures (Tsuchiya, 2013), the stability field is expanded even to the core-mantle boundary for Al-rich phase H (Nishi et al., 2014). Similarly, Al-rich phase D has been shown to have a stability field that extends into the lower mantle (Pamato et al., 2014). Thus, these recent findings motivate questions regarding the properties and stability of hydrous phases and melt at lower mantle conditions. However, the stability of water in the upper mantle and transition zone is still not resolved (Green et al., 2010). 
Smyth et al. (2004) propose that the magnitude of seismic velocity variations due to changes in water content in ringwoodite could be larger than those from temperature variations. However, the discontinuity structure is most consistent with water (elevated 410 and depressed $660 \mathrm{~km}$ discontinuity) in the circum-Pacific subduction zones, but the seismic velocities are usually fast, which is expected for a cold subducting slab. Likewise, a large region of slow seismic velocities exists under the Pacific as predicted for water, but there is a strong, high quality signal indicating that the $410 \mathrm{~km}$ discontinuity topography is depressed. Since the best quality discontinuity topography measurements are within the Pacific, the absence of bins consistent with water there is a strong argument against widespread or global storage of water in the transition zone. While it is possible that hydration produces seismic signals that are weaker or different than the current mineral physics data suggest, there is currently almost no evidence in the global seismic data that water from subduction or the deep mantle from the early Earth is slowly hydrating the mantle transition zone.

\section{Conclusion}

Examining the long period seismic observations of discontinuity topography from SS precursors along with shear velocity from a global shear velocity model, there are only a few, scattered locations consistent with the signal of water as predicted by mineral physics. The amount of water indicated is around $0.6 \mathrm{wt} . \%$ considering both the 410 and $660 \mathrm{~km}$ discontinuity topography and shear velocity in these locations. These results indicate that the mantle transition zone is generally dry, containing around one ocean of water.

\section{Acknowledgements}

This work was funded by the National Science Foundation EAR1114445 and the Earth-Life Science Institute at Tokyo Institute of Technology. The facilities of the Incorporated Research Institutions for Seismology (IRIS) Data Services, specifically the IRIS Data Management Center and the EarthScope USArray facility, were used for access to waveforms, related metadata, and/or derived products used in this study. IRIS Data Services are funded through the Seismological Facilities for the Advancement of Geoscience and EarthScope (SAGE) Proposal of the National Science Foundation under Cooperative Agreement EAR-1261681. Global Seismographic Network (GSN) is a cooperative scientific facility operated jointly by the Incorporated Research Institutions for 
261

262

263 264

Seismology (IRIS), the United States Geological Survey (USGS), and the National Science Foundation (NSF), under Cooperative Agreement EAR-1261681. The author would like to thank Nicholas Guttenberg and members of the Deep Thoughts discussion group for exchanges that contributed to this work. 
Angel, R., Frost, D., Ross, N., Hemley, R., 2001. Stabilities and equations of state of dense hydrous magnesium silicates. Phys. Earth Planet. Int. 127, 181-196.

Bassin, C., Laske, G., Masters, G., 2000. The current limits of resolution for surface wave tomography in North America. EOS 81, 897.

Benz, H., Vidale, J., 1993. The sharpness of upper mantle discontinuities determined by highfrequency P'P' precursors. Nature 365, 147-150.

Bolfan-Casanova, N., McCammon, C., Mackwell, S., 2006. Water in the transition zone and lower mantle minerals. In: Jacobsen, S., van der Lee, S. (Eds.), Earth's Deep Water Cycle. Vol. 168. Geophysical Monograph Series, pp. 57-68.

Cammarano, F., Romanowicz, B., 2007. Insights into the nature of the transition zone from physically constrained inversion of long-period seismic data. Proc. Nat. Acad. Sci. 104, 9139-9144.

Deuss, A., 2009. Global observations of mantle discontinuities using $S S$ and $P P$ precursors. Surv. Geophys. 30, 301-326.

Deuss, A., Andrews, J., Day, E., 2013. Seismic observations of mantle discontinuities and their mineralogical and dynamical interpretation. In: Karato, S. (Ed.), Physics and Chemistry of the Deep Earth. John Wiley and Sons, Ltd., pp. 297-323.

Dixon, J., Leist, L., Langmuir, C., Schilling, J., 2002. Recycled dehydrated lithosphere observed in plume-influenced mid-ocean-ridge basalt. Nature 420, 385-389.

Dziewonski, A., Anderson, D., 1981. Preliminary reference Earth model. Phys. Earth Planet. Int. $25,297-356$.

Flanagan, M., Shearer, P., 1998. Global mapping of topography on transition zone discontinuities by stacking of $S S$ precursors. J. Geophys. Res. 103, 2673-2692.

Green, H., Chen, W.-P., Brudzinski, M., 2010. Seismic evidence of neglibible water carried below 400-km depth in subducting lithosphere. Nature 467, 828-831.

Gu, Y., Dziewonski, A., Ekstrom, G., 2003. Simultaneous inversion for mantle shear velocity and topography of transition zone discontinuities. Geophys. J. Int. 154, 559-583. 
Helffrich, G., 2002. Thermal variations in the mantle inferred from $660 \mathrm{~km}$ discontinuity topography and tomographic wave speed variations. Geophys. J. Int. 151, 935-943.

Helffrich, G., Wood, B., 1996. $410 \mathrm{~km}$ discontinuity sharpness and the form of the olivine $\alpha-\beta$ phase diagram: resolution of apparent seismic contradictions. Geophys. J. Int. 126, F7-F12.

Higo, Y., Inoue, T., Yurimoto, H., 2001. Effect of water on spinel-postspinel transformation in $\mathrm{Mg}_{2} \mathrm{SiO}_{4}$. Geophys. Res. Lett. 28, 3505-3508.

Hirose, K., 2002. Phase transitions in pyrolitic mantle around 670-km depth: Implications for upwelling of plumes from the lower mantle. J. Geophys. Res. 107, doi:10.1029/2001JB000597.

Hirschmann, M., 2006. Water, melting, and the deep Earth $\mathrm{H}_{2} \mathrm{O}$ cycle. Annu. Rev. Earth Planet. Sci. 34, 629-653.

Houser, C., Masters, G., Flanagan, M., Shearer, P., 2008a. Determination and analysis of longwavelength transition zone structure using $S S$ precursors. Geophys. J. Int. 174, 178-194.

Houser, C., Masters, G., Shearer, P., Laske, G., 2008b. Shear and compressional velocity models of the mantle from cluster analysis of long-period waveforms. Geophys. J. Int. 174, 195-212.

Houser, C., Williams, Q., 2010. Reconciling Pacific 410 and $660 \mathrm{~km}$ discontinuity topography, transition zone shear velocity patterns, and mantle phase transitions. Earth Planet. Sci. Lett. $296,255-266$.

Huang, X., Xu, Y., Karato, S., 2005. Water content in the transition zone from electrical conductivity of wadsleyite and ringwoodite. Nature 434, 746-749.

Inoue, T., Tanimoto, Y., Irifune, T., Suzuki, T., Fukui, H., Ohtaka, O., 2004. Thermal expansion of wadsleyite, ringwoodite, hydrous wadsleyite and hydrous ringwoodite. Phys. Earth Planet. Int. 143-144, 279-290.

Inoue, T., Wada, T., Sasaki, R., Yurimoto, H., 2010. Water partioning in the Earth's mantle. Phys. Earth Planet. Int. 183, 245-251.

Inoue, T., Yurimoto, H., Kudoh, Y., 1995. Hydrous modified spinel, $\mathrm{Mg}_{1.75} \mathrm{SiH}_{0.5} \mathrm{O}_{4}$, a new water reservoir in the mantle transition zone. J. Geophys. Res. 22, 117-120. 
Jacobsen, S., Smyth, J., 2006. Effect of water on the sound velocities of ringwoodite in the transition zone. In: Jacobsen, S., van der Lee, S. (Eds.), Earth's Deep Water Cycle. American Geophysical Union, pp. 131-145.

Kohlstedt, D., Keppler, H., Rubie, D., 1996. Solubility of water in the $\alpha, \beta$, and $\gamma$ phases of $(\mathrm{Mg}, \mathrm{Fe})_{2} \mathrm{SiO}_{4}$. Contributions to Mineral Petrology 123, 345-357.

Lawrence, J., Shearer, P., 2008. Imaging mantle transition zone thickness with $S d S$-SS finitefrequency sensitivity kernels. Geophys. J. Int. 174, 143-158.

Lessing, S., Thomas, C., Rost, S., Cobden, L., Dobson, D., 2014. Mantle transition zone structure beneath India and Western China from migration of PP and SS precursors. Geophys. J. Int. 197, $396-413$.

Litasov, K., Ohtani, E., Sano, A., Suzuki, A., Funakoshi, K., 2005. In situ X-ray diffraction study of post-spinel transformation in a peridotite mantle: Implication for the 660-km discontinuity. Earth Planet. Sci. Lett. 238, 311-328.

Mao, Z., Jacobsen, S., Jian, F., Smyth, J., Holl, C., Duffy, T., 2008. Elasticity of hydrous wadsleyite to 12 GPa: Implications for Earth's transition zone. Geophys. Res. Lett. 35, L21305.

Mao, Z., Lin, J., Jacobsen, S., Duffy, T., Chang, Y., Smyth, J., Frost, D., Hauri, E., Prakapenka, V., 2012. Sound velocities of hydrous ringwoodite to $16 \mathrm{GPa}$ and 673 K. Earth Planet. Sci. Lett. 331-332, 112-119.

Meier, U., Trampert, J., Curtis, A., 2009. Global variations of temperature and water content in the mantle transition zone from higher mode surface waves. Earth Planet. Sci. Lett. 282, 91-101.

Neele, F., 1996. Sharp 400-km discontinuity from short-period P reflections. Geophys. Res. Lett. $23,419-422$.

Nishi, M., Irifune, T., Tsuchiya, J., Tange, Y., Nishihara, Y., Fujino, K., Higo, Y., 2014. Stability of hydrous silicate at high pressures and water transport to the deep lower mantle. Nature Geoscience 7, 224-227.

Ohtani, E., Mizobata, H., Yurimoto, H., 2000. Stability of dense hydrous magnesium silicate phases in the systems $\mathrm{Mg}_{2} \mathrm{SiO}_{4}-\mathrm{H}_{2} \mathrm{O}$ and $\mathrm{MgSiO}_{3}-\mathrm{H}_{2} \mathrm{O}$ at pressures up to $27 \mathrm{GPa}$. Physics and Chemistry of Minerals 27, 533-544. 
Pamato, M., Myhill, R., Ballaran, T., Frost, D., Heidelbach, F., Miyajima, N., 2014. Lower-mantle water reservoir implied by the extreme stability of a hydrous aluminosilicate. Nature Geoscience $8,75-79$.

Pearson, D., Brenker, F., Nestola, F., McNeill, J., Nasdala, L., Hutchison, M., Matveev, S., Mather, K., Siversmit, G., Schmitz, S., Vekemans, B., Vincze, L., 2014. Hydrous mantle transition zone indicated by ringwoodite included within diamond. Nature 507, 221-224.

Ritsema, J., van Heijst, H., Woodhouse, J., 2004. Global transition zone tomography. J. Geophys. Res. 109, 10.1029/2003JB002610.

Schmerr, N., Garnero, E., 2007. Upper mantle discontinuity topography from thermal and chemical heterogeneity. Science 318, 623-626.

Smyth, J., Frost, D., 2002. The effect of water on the 410-km discontinuity: An experimental study. Geophys. Res. Lett. 29, doi:10.1029/2001GL014418.

Smyth, J., Holl, C., Frost, D., Jacobsen, S., 2004. High pressure crystal chemistry of hydrous ringwoodite and water in the Earth's interior. Phys. Earth Planet. Int. 143-144, 271-278.

Stampfli, G., Borel, G., 2002. A plate tectonic model for the Paleozoic and Mesozoic constrained by dynamic plate boundaries and restored synthetic oceanic isochrons. Earth Planet. Sci. Lett. $196,17-33$.

Stixrude, L., 1997. Structure and sharpness of phase transitions and mantle discontinuities. J. Geophys. Res. 102, 14835-14852.

Suetsugu, D., Inoue, T., Yamada, A., Zhao, D., Obayashi, M., 2006. Towards mapping the threedimensional distribution of water in the transition zone from P-velocity tomography and 660-km discontinuity depths. In: Jacobsen, S., van der Lee, S. (Eds.), Earth's Deep Water Cycle. Vol. 168. Geophysical Monograph Series, pp. 237-249.

Thio, V., Cobden, L., Trampert, J., 2016. Seismic signature of a hydrous mantle transition zone. Physics Earth. Planet. Int. 250, 46-63.

Tsuchiya, J., 2013. First principles prediction of a new high-pressure phase of dense hydrous magnesium silicates in the lower mantle. Geophys. Res. Lett. 40, 4570-4573. 
Tsuchiya, J., Tsuchiya, T., 2009. First principles investigation of the structural and elastic properties of hydrous wadsleyite under pressure. J. Geophys. Res. 114, doi:10.1029/2008JB005841.

Wood, B., 1995. The effect of $\mathrm{H}_{2} \mathrm{O}$ on the 410-kilometer seismic discontinuity. Science 268, 74-76.

Xu, F., Vidale, J., Earle, P., 2003. Survey of precursors to P'P': Fine structure of mantle discontinuities. J. Geophys. Res. 108, doi:10.1029/2001JB000817.

Zheng, Y., Lay, T., Flanagan, M., Williams, Q., 2007. Pervasive seismic wave reflectivity and metasomatism of the Tonga mantle wedge. Science 316, 855-859. 


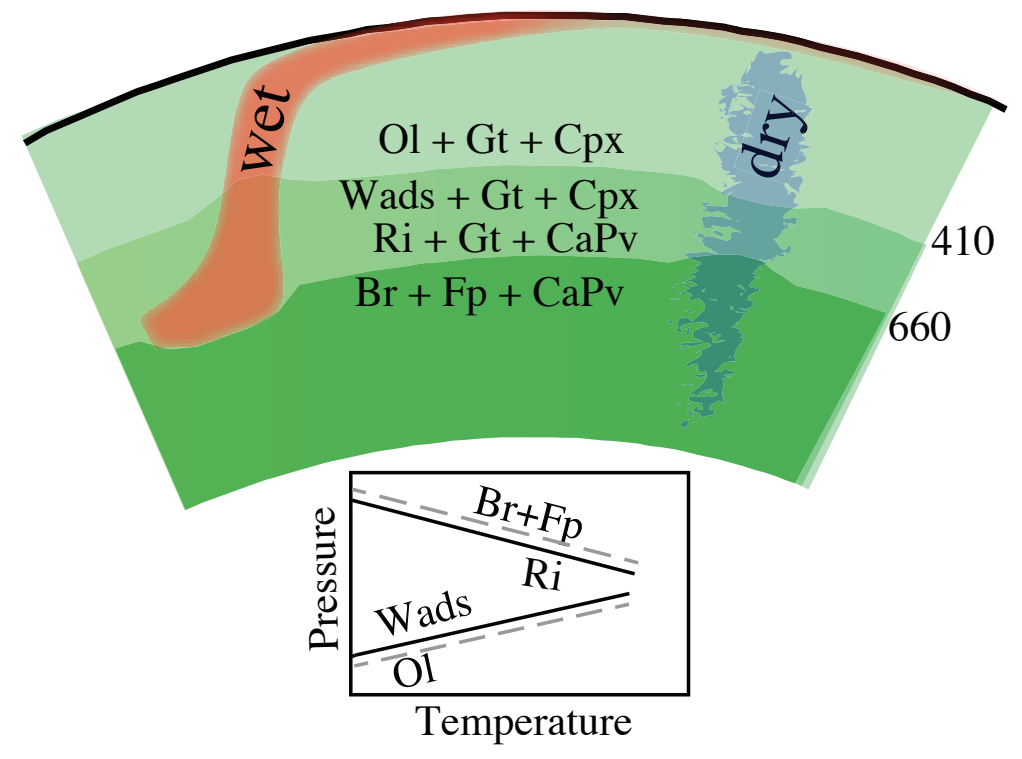

Figure 1: Cartoon representing the predicted behavior (see Jacobsen and Smyth (2006)) of transition zone phases in the presence of a downwelling wet slab or dry mantle upwelling colored red/blue because water reduces shear velocity (ignoring temperature). The schematic phase diagram shows the Clapeyron slopes of dry (black solid) and wet (grey dashed) olivine component of the mantle. $\mathrm{Ol}=$ olivine, $\mathrm{Gt}=$ garnet, $\mathrm{Cpx}=$ clinopyroxene, Wads $=$ wadsleyite, $\mathrm{Ri}$ $=$ ringwoodite, $\mathrm{CaPv}=$ calcium perovskite, $\mathrm{Br}=$ bridgmanite, and $\mathrm{Fp}=$ ferropericlase 


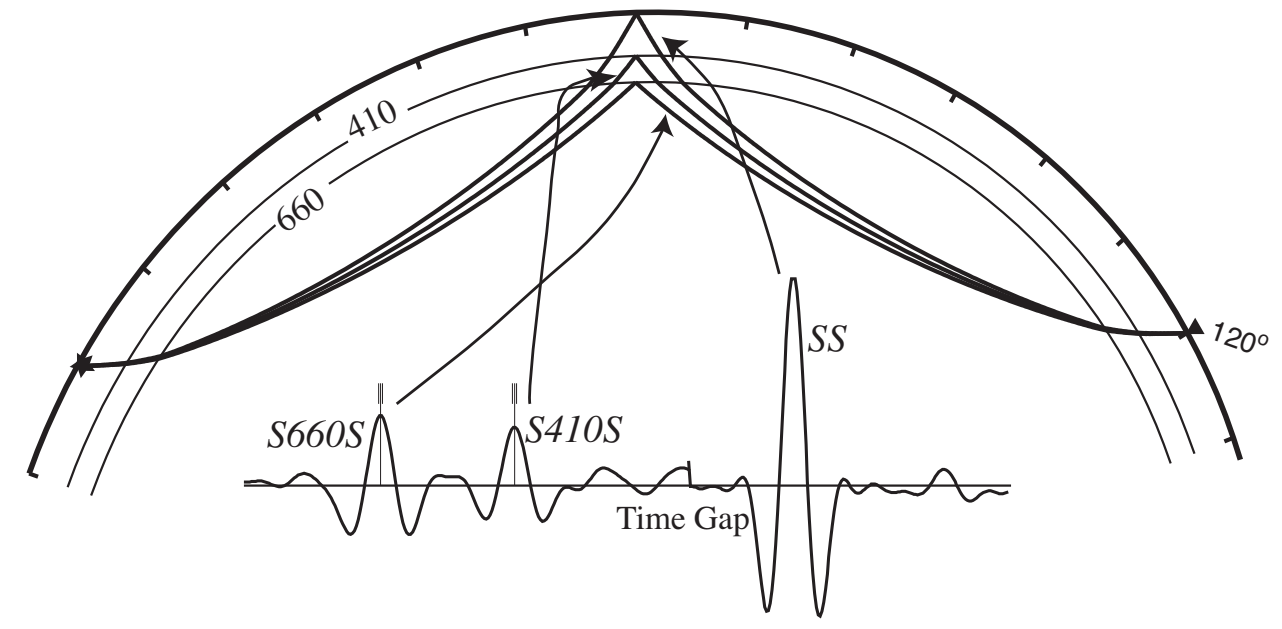

Figure 2: Ray geometry of SS precursors, and an actual precursor stack used in this study from the NW Pacific including 1133 seismograms. There is a time gap between the main SS arrival and the precursors. The vertical lines at the pulse peak are the SdS arrival times and the small grey lines above the pulse represent the error in the pulse peak from the bootstrap random resampling. 


\section{Improved Stack Quality}

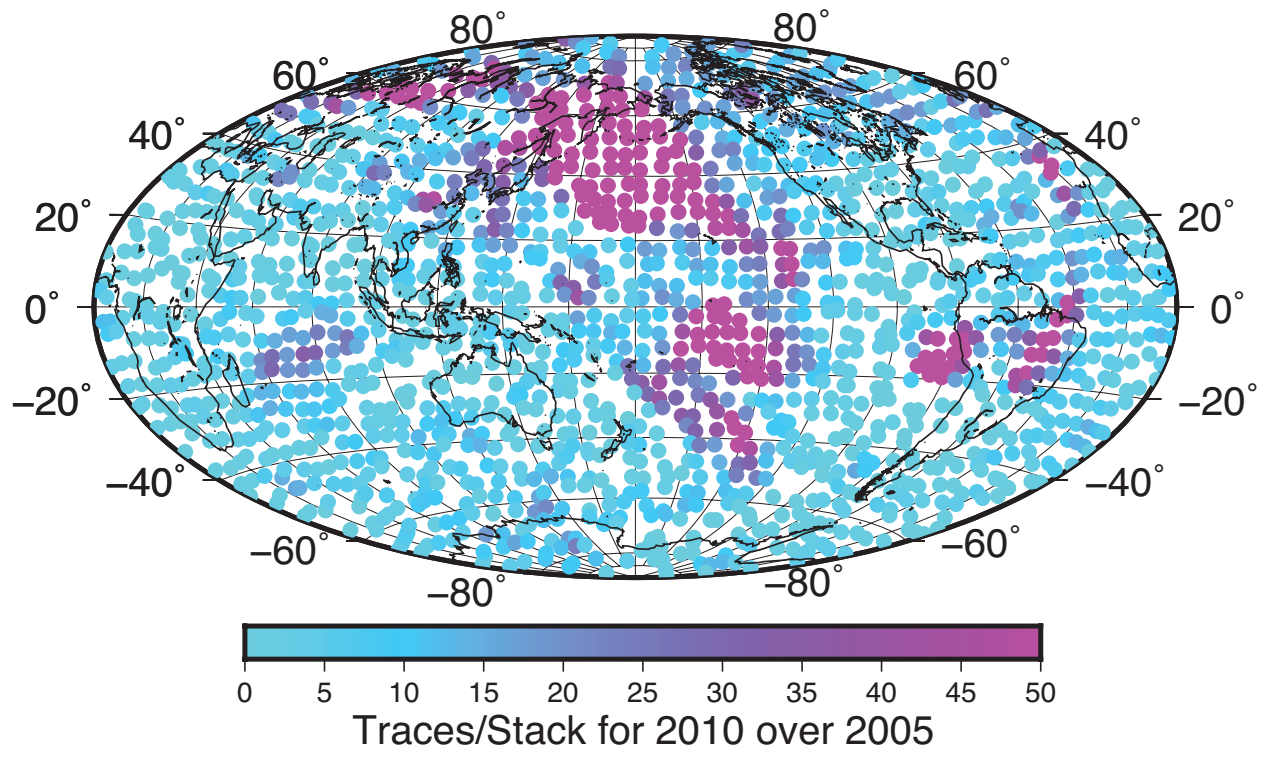

Figure 3: Map of the increase in the number of traces per stack for this study using data through 2010 versus the previous Houser et al. (2008a) study which has data through 2005. Dark pink regions have significant improvement in the quality of the SS precursor stacks due to more traces contributing to the stack. The color scale saturates at 50 traces/stack, but stacks in the central Pacific have increases of over 500 traces/stack. Improvement occurs in the northern Pacific, southern Pacific, eastern Asia, Indian ocean, northern South America, and north Atlantic. Light blue regions have almost the same stack quality as the previous study. 

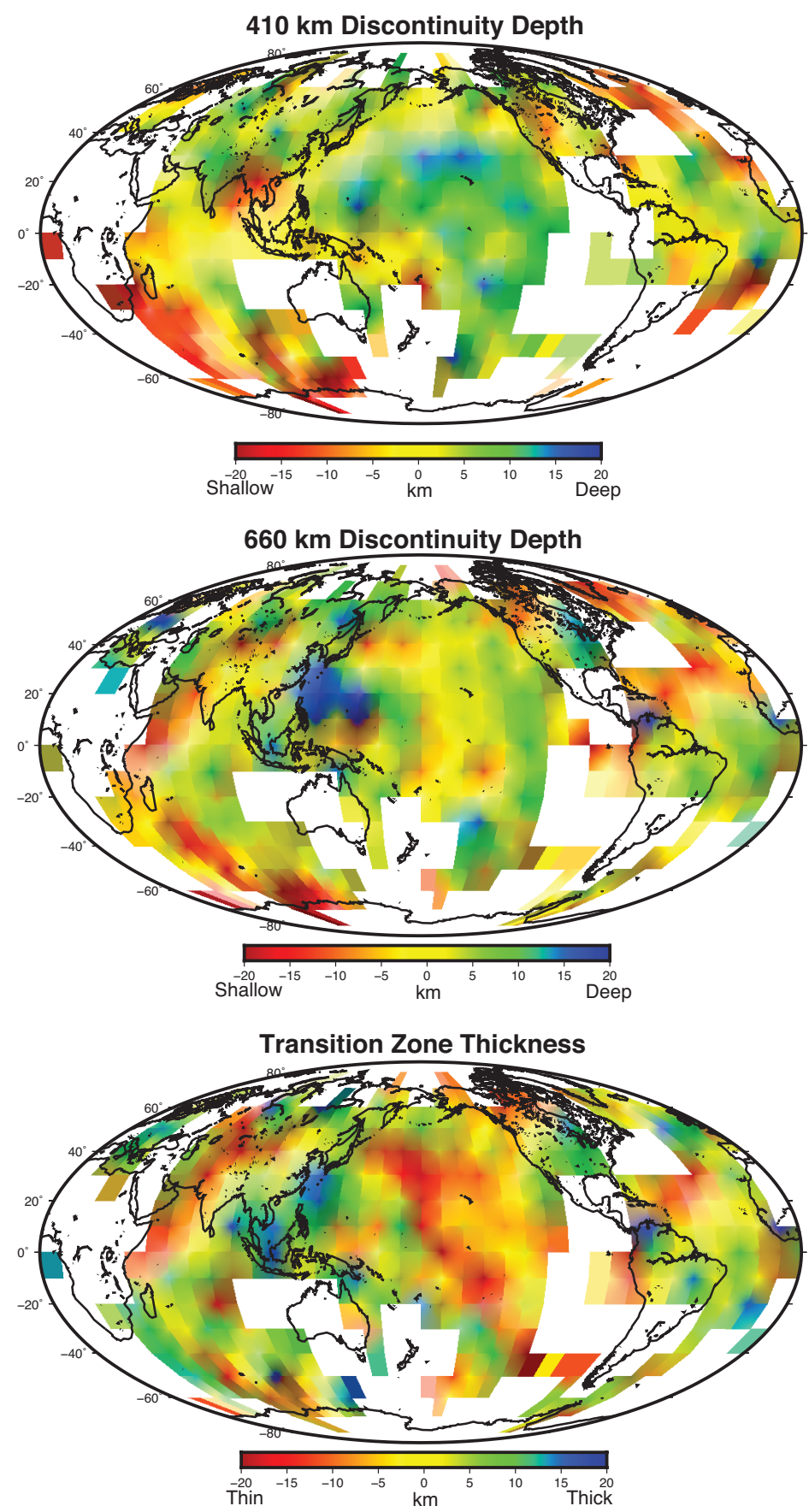

Figure 4: Topography of the 410 and $660 \mathrm{~km}$ discontinuities and the resulting transition zone thickness where the topography is defined as the elevation above and the below the average of $411 \mathrm{~km}, 650 \mathrm{~km}$, and $239 \mathrm{~km}$ respectively. Only bins for which the number of traces/stack is greater than 15 and the depth error is less than $20 \mathrm{~km}$ are shown which reduces the bin number from 1464 to 1301. 


\section{Shear Velocity at the Base}

of the Transition Zone

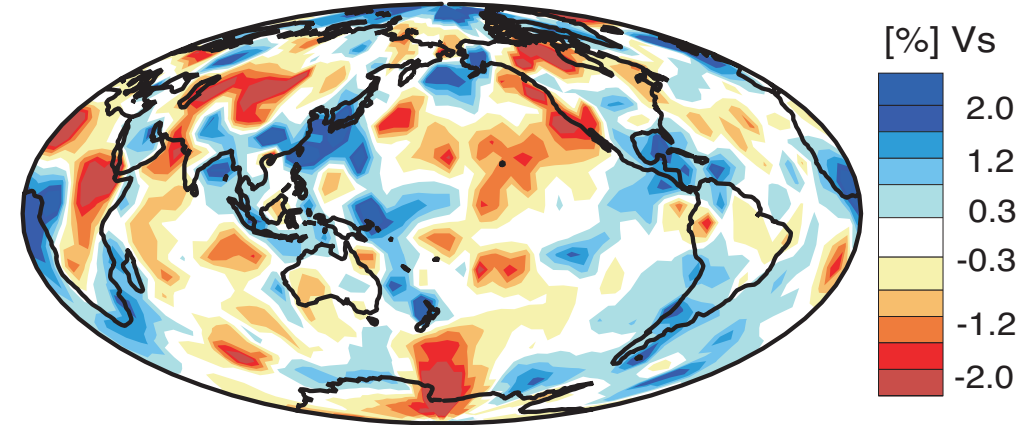

Figure 5: Shear velocity of the mantle transition zone from 530-660 km depth. The model is the same as HMSL-S06 (Houser et al., 2008b), but the tomographic inversion is performed with $6^{\circ}$ instead of $4^{\circ}$ equal-area blocks at the equator. This velocity model is compared to the topography plotted in Figure 4 to create the comparison map in Figure 6 . 




Figure 6: Maps of the western and eastern hemispheres where each circle represents the relative discontinuity topography from the global average in each $5^{\circ}$ bin. The color-coding scheme distinguishes bins by the sign seismic velocity anomaly and the elevation of both discontinuities. The purple bins which are consistent with the predictions for water are shown magnified in the right column, but represent only $8 \%$ of the 1301 bins used for this analysis. 

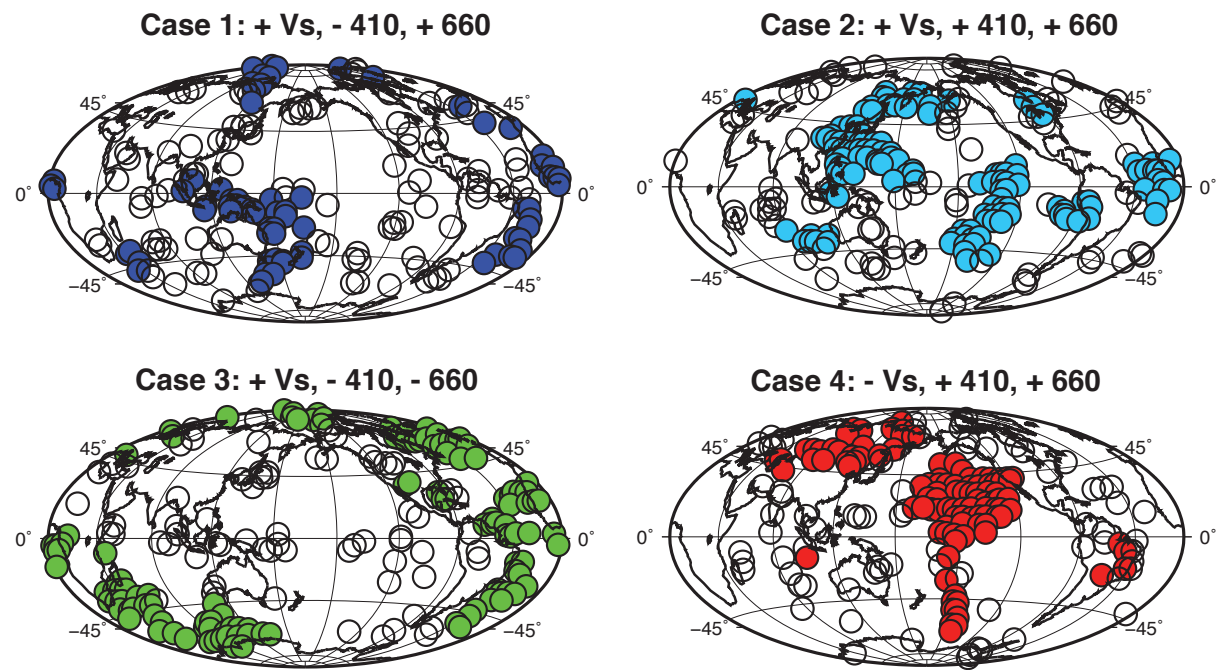

Case 4: - Vs, $+410,+660$
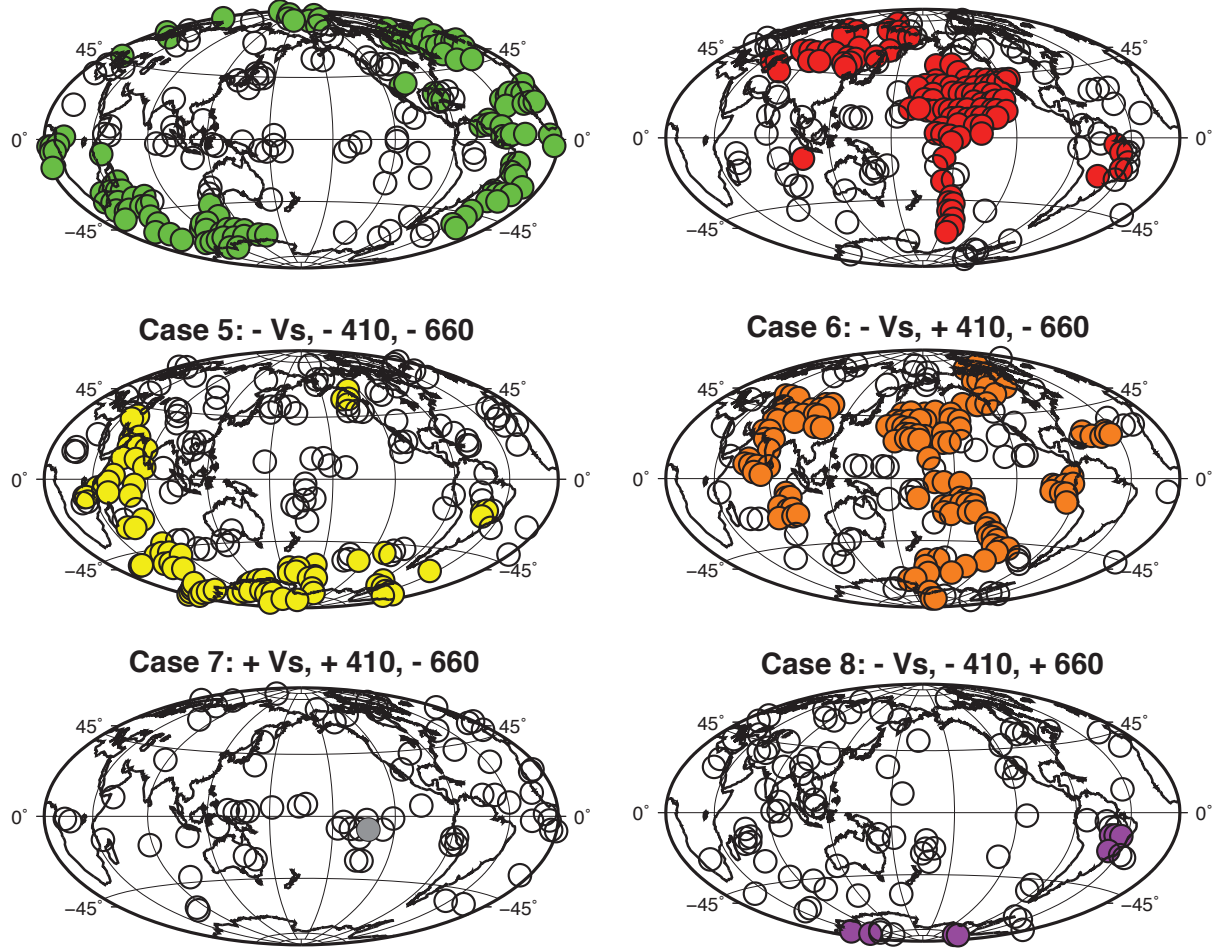

Figure 7: Maps highlighting where each of the 8 observed discontinuity topography - shear velocity relationship cases have more neighboring bins with the same value than expected from a random process. Bins for which there are more neighboring bins than random are filled using the same color-coding scheme as in Figure 6. Empty circles are bin locations for which the neighboring bins (within $20^{\circ}$ ) with the same value occur less than $2 \sigma+$ mean times. $+\mathrm{Vs}=$ fast, $-\mathrm{Vs}=$ slow, $-410 / 660=$ shallow,$+410 / 660=$ deep. Case 8 (bottom right, purple) is the velocity/topography relationship that is expected for water in the transition zone. Cases 1 (cold) and 6 (warm) represent the expected relationship for velocity/topography with temperature. This analysis demonstrates that the temperature signal has much stronger regional trends than the water signal. 

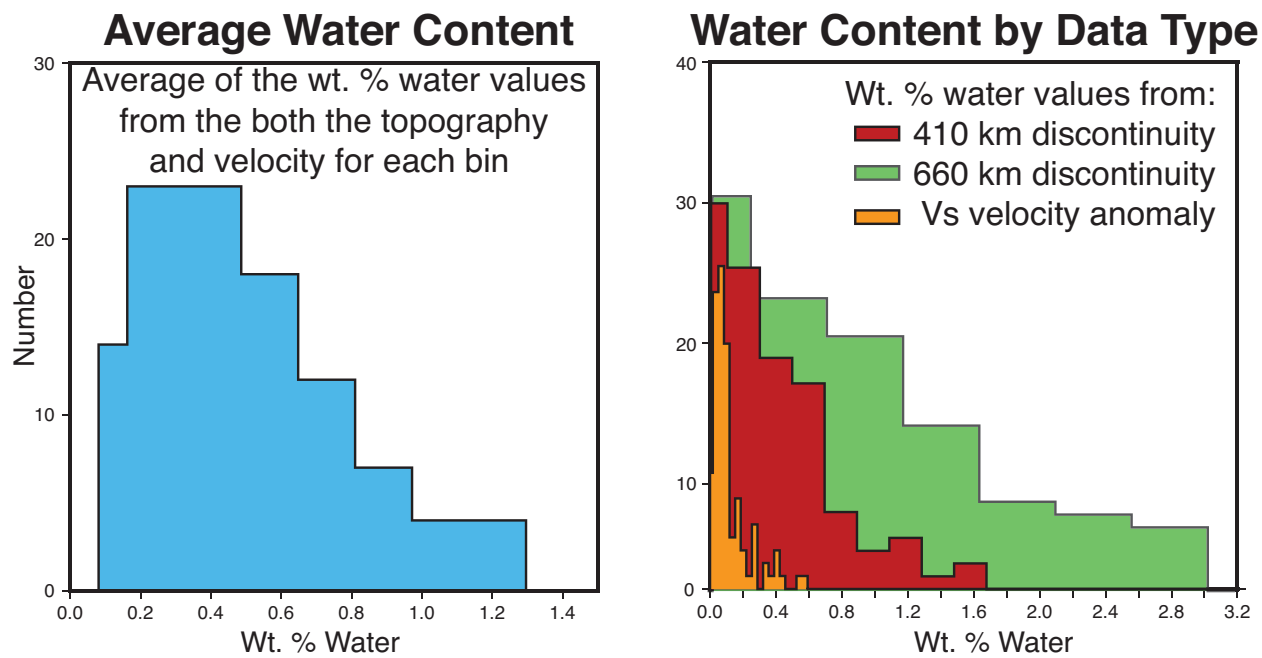

Figure 8: Left: The distribution of average water concentration values $\left(410_{\text {value }}+660_{\text {value }}+V s_{\text {value }}\right) / 3$ from each bin with a seismically consistent water signal. The overall average of these values is 0.6 wt.\% water. Right: water concentration values from each type of data; $410 \mathrm{~km}$ discontinuity topography, $660 \mathrm{~km}$ discontinuity topography, and shear velocity anomaly. 